\title{
Is it time to rethink the urea criterion in CURB-65?
}

\section{To the Editors:}

We read the article by CAPELASTEGUI et al. [1] on the validation of the severity assessment rules for the management of community-acquired pneumonia (CAP) with interest. The authors concluded that CURB-65 (confusion, urea $>7 \mathrm{mmol}$. $\mathrm{L}^{-1}$, respiratory rate $\geqslant 30 \cdot \mathrm{min}^{-1}$, low systolic $(<90 \mathrm{mmHg})$ or diastolic $(\leqslant 60 \mathrm{mmHg}$ ) blood pressure, and aged $\geqslant 65 \mathrm{yrs})$ and CRB-65 indices recommended by the British Thoracic Society are indeed useful and easy to apply in day-to-day clinical practice, thereby helping in risk stratification and management as demonstrated by LIM et al. [2].

With the current demographic trends, the proportion of the older population is set to rise. Globally, the projected number of people aged $\geqslant 65$ yrs will double between 2000 and 2030 [3]. Moreover, CAP is common in older people and is associated with high mortality [4]. We note that the mean ages of patients reported in CAPELASTEGUI et al. [1] and LIM et al. [2] were 64.1 and $61.8 \mathrm{yrs}$, respectively. In a prospective study of elderly patients aged $\geqslant 65$ yrs with CAP (mean \pm SD age $81.1 \pm 7.9$ yrs), we reported that the sensitivity and specificity of CURB in predicting death were 81 and $52 \%$, respectively [5]. The specificity figure of this elderly cohort was much lower than in other studies of younger patients $[2,6,7]$. Due to this low specificity, the CURB-65 criteria in their current form are not ideal for assessing older CAP patients.

In the same study, we found that the urea criterion was only of borderline significance and cautioned that the urea cut-off point of $>7 \mathrm{mmol} \cdot \mathrm{L}^{-1}$ in the CURB criteria may not be a sufficiently specific parameter [5]. This may be due to the fact that chronic renal impairment is more prevalent in the older population, and dehydration, which is common in acutely unwell older patients, may also contribute to a higher urea level [8]. With this background, we set out to assess whether raising the cut-off point of urea, while keeping the other criteria in CURB-65 as they are, would improve the specificity and positive predictive value (PPV) of the criteria in predicting mortality.

Analyses were conducted based on data from two prospective cohort studies [5,7], which were carried out in a single institute in UK using similar inclusion and exclusion criteria. Although all ages were included in the first study [7], in the second study only those who were aged $\geqslant 65$ yrs were included [5]. Therefore, the compilation cohort consisted of a higher number of older patients with CAP and a higher mean age (mean \pm SD age $70.3 \pm 18.2$ yrs) compared with previously reported studies.

A total of 193 patients were included in the currently reported analysis. It was hypothesised that increasing the urea cut-off level in older people would improve the specificity of CURB65. This hypothesis was tested by increasing the urea cutoff point by $2 \mathrm{mmol} \cdot \mathrm{L}^{-1}$ each time from the currently recommended urea cut-off level of $>7 \mathrm{mmol} \cdot \mathrm{L}^{-1}$ (i.e. CU9RB65 with urea cut-off $>9 \mathrm{mmol} \cdot \mathrm{L}^{-1}, \mathrm{CU} 11 \mathrm{RB}-65$ using urea cutoff $>11 \mathrm{mmol} \cdot \mathrm{L}^{-1}$ and CU13RB-65 using urea cut-off $>13 \mathrm{mmol} \cdot \mathrm{L}^{-1}$ ), and the sensitivities, specificities, PPVs and negative predictive values (NPVs) for these indices in predicting 6-week mortality outcome were examined.

It was found that the specificity and PPV do increase with a rising cut-off level of urea, but there was a corresponding drop in sensitivity. A linear increase in PPVs was observed along with a slight decrease in NPVs. The resulting sensitivities, specificities, PPVs and NPVs are presented in table 1 in comparison with corresponding values for predicting death by CU7RB-65 (urea cut-off point $>7 \mathrm{mmol} \cdot \mathrm{L}^{-1}$ ) in the same cohort.

A large prospective study to verify these findings is certainly desirable, particularly in view of the demographic trend towards an ageing population. Whilst we agree with the editorial comment by EWIG et al. [9] that, at present, CURB-65 (confusion, urea $>7 \mathrm{mmol} \cdot \mathrm{L}^{-1}$, respiratory rate $\geqslant 30 \cdot \mathrm{min}^{-1}$, low blood pressure, and aged $\geqslant 65 \mathrm{yrs}$ ) and CRB-65 should be the tools of choice for severity assessment in community-acquired pneumonia, it is possible to improve the specificity of identifying true severe cases in older adults by raising the urea cut-off level to a more discriminative value.

\section{A.V. Kamath*, P.K. Myint ${ }^{*}$, , S.L. Vowler ${ }^{\#}$ and B.D.W. Harrison $*$,}

*Norfolk and Norwich University Hospital, "University of East Anglia, Norwich, and "Centre for Applied Medical Statistics, University of Cambridge, Cambridge, UK.

TABLE 1
$\begin{aligned} & \text { Sensitivities, specificities, PPVs and NPVs for the different indices using incrementally higher urea cut-off points in } \\ & \text { CURB-65 }{ }^{*} \text { for predicting death when the total score is } \geqslant 3\end{aligned}$




\section{REFERENCES}

1 Capelastegui A, Espana PP, Quintana JM, et al. Validation of a predictive rule for the management of communityacquired pneumonia. Eur Respir J 2006; 27: 151-157.

2 Lim WS, van der Eerden MM, Laing R, et al. Defining community acquired pneumonia severity on presentation to hospital: an international derivation and validation study. Thorax 2003; 58: 377-382.

3 World Population at a Glance: 1998 and beyond. U.S. Dept of Commerce, Economics and Statistics Administration, Bureau of the Census, IB /98-4, International Brief, 1999. www.census.gov/ipc/prod/wp98/ib98-4.pdf. Date last accessed: March 212006.

4 Woodhead MA. Pneumonia in the elderly. I Antimicrob Chemother 1994; 34: Suppl. A, 85-92.

5 Myint PK, Kamath AV, Vowler SL, Maisey DN, Harrison BD. The CURB (confusion, urea, respiratory rate and blood pressure) criteria in community-acquired pneumonia (CAP) in hospitalised elderly patients aged 65 years and over: a prospective observational cohort study. Age Ageing 2005; 34: 75-77.

6 Neill AM, Martin IR, Weir R, et al. Community acquired pneumonia: aetiology and usefulness of severity criteria on admission. Thorax 1996; 51: 1010-1016.

7 Kamath A, Pasteur MC, Slade MG, Harrison BD. Recognising severe pneumonia with simple clinical and biochemical measurements. Clin Med 2003; 3: 54-56.

8 Warren JL, Bacon WE, Harris T, McBean AM, Foley DJ, Phillips C. The burden and outcome associated with dehydration among United States elderly, 1991. Am J Public Health 1991; 84: 1265-1269.

9 Ewig S, Torres A, Woodhead M. Assessment of pneumonia severity: a European perspective. Eur Respir J 2006; 27: 6-8.

\section{Flawed interpretative strategies for lung function tests harm patients}

\section{To the Editors:}

"The devil's in the details" of the new American Thoracic Society (ATS)/European Respiratory Society (ERS) document regarding the interpretation of pulmonary function test (PFT) results [1]. As a member of the Task Force, I was happy for the opportunity to help standardise the way in which clinically important PFTs are performed and interpreted. Unfortunately, the group spent almost all of the 3 yrs reaching an agreement (or compromise) on the mechanics of making accurate spirometry, diffusing capacity of the lung for carbon monoxide and lung volume measurements, but left inadequate time to thoroughly discuss the more important but controversial aspects of interpretation. A consensus was not reached, and thus, should not be inferred by publication of the document. In my opinion, the strategy for interpreting the presence of "obstructive abnormalities" is the detail with the highest potential for causing harm to patients.

This new strategy suggests interpreting a low forced expiratory volume in one second (FEV1)/vital capacity (VC) with a normal FEV1 as mild obstruction (see fig. 2 and table 6 in [1]). Previous documents have considered this pattern as a "normal physiological variant," normal, or borderline abnormal [2], since no associations with clinical disease or increased risk of future disease have been established for this pattern. In 2001, the Global Initiative for Chronic Obstructive Lung Disease (GOLD) guidelines [3] were the first to consider this pattern (post-bronchodilator) to indicate mild COPD (even in patients without respiratory symptoms), followed by the ATS/ERS guidelines [4], but neither provides any evidence for this change. The latest British Thoracic Society guidelines for mild COPD [5], however, used the traditional definition of a low
FEV1/forced vital capacity (FVC) and an FEV1 $<80 \%$ of predicted. The apparent COPD prevalence rate is doubled when this new definition is applied to adults; and even tripled in those aged $>65$ yrs [6].

The new strategy also suggests interpreting the common "nonspecific" pattern of normal FEV1/VC with a low FVC (sometimes called spirometric restriction) as mild obstruction (fig. 2 in [1]), at least when the total lung capacity is normal (ruling out true restriction of lung volumes). However, I'm unaware of any studies describing the clinical correlates or subsequent outcomes of groups of patients with this pattern.

If widely followed, I believe that this new strategy will: 1) more than double the apparent prevalence of mild airway obstruction; 2) increase the rate of falsely positive interpretations; 3) raise the number of prescriptions for inhaled medications for those who won't benefit from them; and 4) increase the financial, physical and psychological side-effects of these medications. A recent study from 50 sites in Europe [7] found that $75 \%$ of study participants with mild COPD (GOLD stage II) were already taking inhaled corticosteroids, despite the fact that no inhaled medication has been found to improve clinical outcomes in patients with an FEV1 $>50 \%$ pred [8].

Like others before it, this new interpretative strategy is likely to be programmed into the spirometers purchased by both pulmonologists and primary care providers. When the computerised interpretation says "mild obstruction," most doctors believe it.

\section{P. Enright}

College of Public Health, The University of Arizona, Tucson, AZ, USA. 